\title{
Life Cycle Assessment of Municipal Waste Management System (Case Study: Karaj, Iran)
}

\section{${ }^{*}$ S. SHAHRAM NAGHIBZADEH ${ }^{1}$, NEMATOLAH KHORASANI ${ }^{2}$, JAVAD YOUSEFI $^{3}$, B. SOMAYEH MOUSAVI ${ }^{4}$, ZIAEDIN BADEHIAN $^{5}$}

\author{
${ }^{1,3}$ Department of Environment, Velayat University, Iranshahr, Iran \\ ${ }^{2}$ Department of Environment, Collage of Agriculture and Natural Resources, University of Tehran, Karaj, Iran \\ ${ }^{4}$ Department of Electrical Engineering, Hatef Higher Education Institute, Zahedan, Iran \\ ${ }^{5}$ Department of Forestry, Lorestan University, Khoram abad, Iran \\ Email: bbmoosavi@gmail.com
}

KEY WORDS: Waste Management system, LCA, Karaj

\begin{abstract}
LCA has been defined as a tool for evaluating the environmental burdens and potential impacts that can be applied to municipal solid waste management systems for determine the optimum municipal solid waste (MSW) management strategy.To investigate the Waste Management system strategyof Karaj City we used LCA method. Three scenarios were defined and compared based on environmental burden include water pollution, air pollution, consumed energy and waste residues.. For each of these scenarios, an ecological indicator was achieved from checklist values. From the environmental point of view, results show that recycling is one of the best alternatives for Waste Management. Furthermore, composting has an important role in alleviating the load of pollutants and energy usage in the Waste Management system. OJASEM
\end{abstract}

http://dx.doi.org/10.4314/jasem.v18i4.1

\section{Introduction}

Waste Management is a basic need of any society. Regarding the rate of waste production and the composition of the waste, different alternatives might be used for Waste Management systems. Analyzing and comparison of the environmental and technological efficiency of Waste Management systems can be performed using environmental assessment tools. LCA, which is the technique of investigating the environmental aspects relevant to one production or one process in all, over the life period (from birth to burial) of which, is one of the important decision making tools. The approach dominating this study is from cradle to tomb In this concept, different stages of (SETAC, 1998). conducting a process or services are studied In LCA of the waste, the point of .(Powell, 2000) birth, which is known as the cradle, is the door of the house and the burial is known as the tomb. In each stage, consumed resources and outputs are considered. Such processes are considered as a system. Inputs (resources) and outputs (pollutants) are inventoried and finally are assessed and interpreted.

One of the applications of LCA is the comparison of the alternatives and scenarios of the Waste Management and the assessment of consequences of different settled structures in the process of
Municipal solid Waste Management. In Ankara, LCA was used for the comparison of the different methods of Waste Management. In that study, five scenarios, which were applied in Waste Management, were defined and considered. Afterward, the environmental load of each scenario was inventoried and presented. Impact assessment of life cycled was not conducted and by comparison the results of the life cycle inventory, suitable alternatives were chosen and presented. Finally, distance reduction from the source had the least environmental impact and was presented as the best method of solid Waste Management ( Ozeler et al, 2005). Compared with the different alternatives of Waste Management that was done on the basis of energy economizing and lesser environmental impacts in the City of Rome, it showed that recycling the energy by Waste Management could supply the $15 \%$ of required electrical energy for the City (Cherubini et al, 2007).

\section{MATERIAL AND METHODS}

Waste condition in Karaj: On the basis of the last statistics of Karaj Municipal, at the end of 2008, the rate of waste which had been gathered is 1389 ton/day, 969 ton $(70 \%)$ of which are corruptible materials, sludge, and gathered sediments of the city. Figure 1, Shows the graph of produced waste of the City (Organization of Recycle and Transformation Karaj, 2008). 


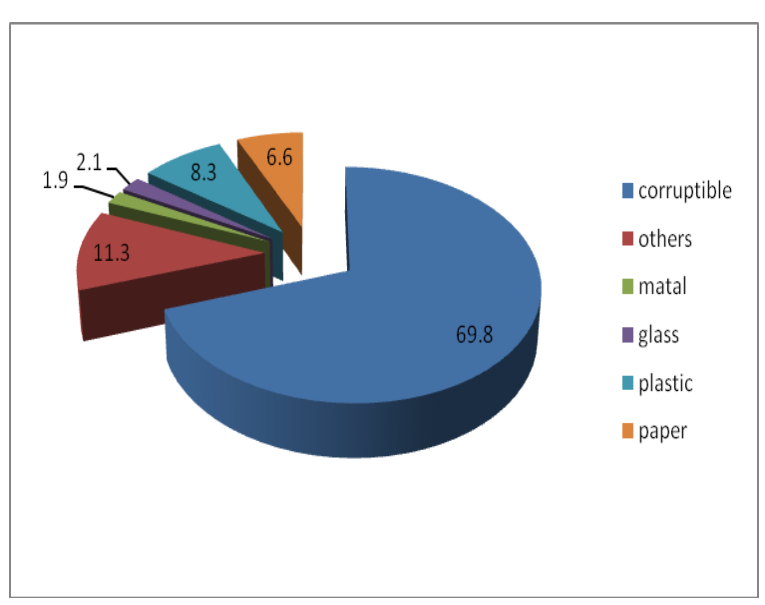

Fig 1 Different kind of waste (O.R.T, Karaj, 2008)

Definition of the goals and scope; The object of this study is to assess the life cycle of the current Waste Management System in Karaj of the environmental viewpoint, and determining the preference in decisions in order to improve the Waste Management. The borders of the object system begin from the waste gathering in front of the door and ends in the landfilling or composting in factory and studied time framework is one year. On the basis of waste production rate (year 2008) three scenarios, and in each scenario relevant management alternatives in the process of the waste production, were developed. Therefore, management alternatives for each scenario were compared on the basis of their environmental load. Environmental loads are assessed on the basis of criteria comprising: water pollution, air pollution, energy consumption and residual waste.

Scenario 1) Collection System Optimizing: On the basis of this scenario, these three alternatives were considered and compared.

Environmental load caused by landfilling of current produced waste.

Environmental load coming from landfilling of waste which is dropped by 10 percent due to a reduction in the origin, without considering the reduction of need to transport by 10 percent in distancec)

Environmental load coming from landfilling of waste which is dropped by 10 percent due to a reduction in the origin, with considering the reduction of need to transport by 10 percent in distance. Management
Life Cycle Assessment (LCA) LCA of the solid Waste Management system of Karaj is done on the basis of ISO 14040 in four steps (Figure 2).

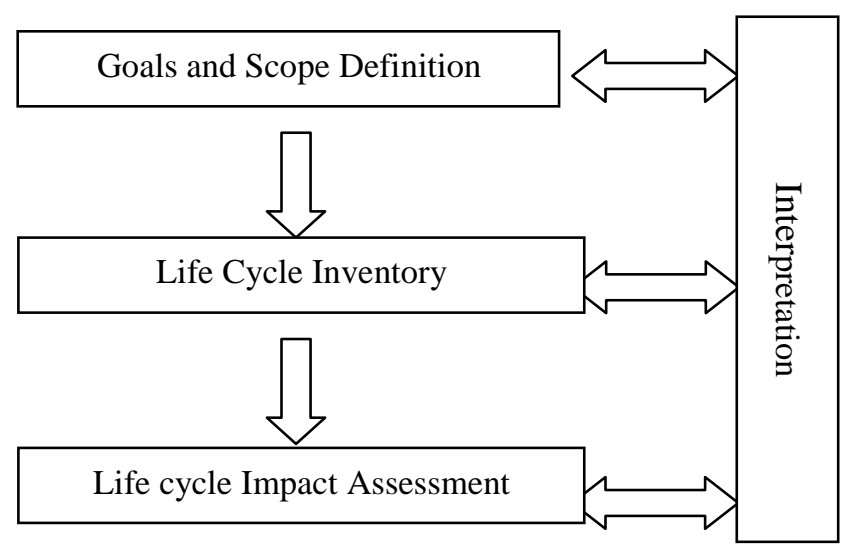

Fig: 2 The two-way relationship between interpretation and the first three steps means that interpretation can be done at each stage to correct the procedure (ISO 14040, 1997)

alternatives considered in this study are for understanding the role of reducing the produced Municipal solid waste (reduction from origin and therefore making the culture and enhancing the quality of the consumed material) and consequently reducing the need for the number of vehicles in the imposed load on the environment .Scenario 2 Transport System Optimizing: On the basis of this scenario two alternatives were considered and compared. Environmental load caused by current waste rate regarding the distance to the landfill (the same as scenario 1 alternative a) Environmental load caused by current waste rate, regarding the $10 \%$ reduction in distance to the landfill due to the use of transfer stations. Management alternatives considered in this scenario are for understanding the role of transfer stations - reduce or increase - in the imposed load on the environment.

Scenario 3 Waste Processing System Optimizing: On the basis of this scenario, three alternatives were: considered and compared.

Environmental load caused by landfilling of current produced waste. (the same as scenario 1 alternative a) Environmental load caused by $10 \%$ reduction of waste due to composting. Environmental load caused by $10 \%$ reduction of waste due to recycling. Management alternatives considered in this scenario are for understanding the role of the process of composting, recycling and landfilling of the Municipal Solid Waste in imposed loads on the environment. Now in Karaj, alternatives to 
composting and landfilling of solid waste are used and the incineration is not prevalent.

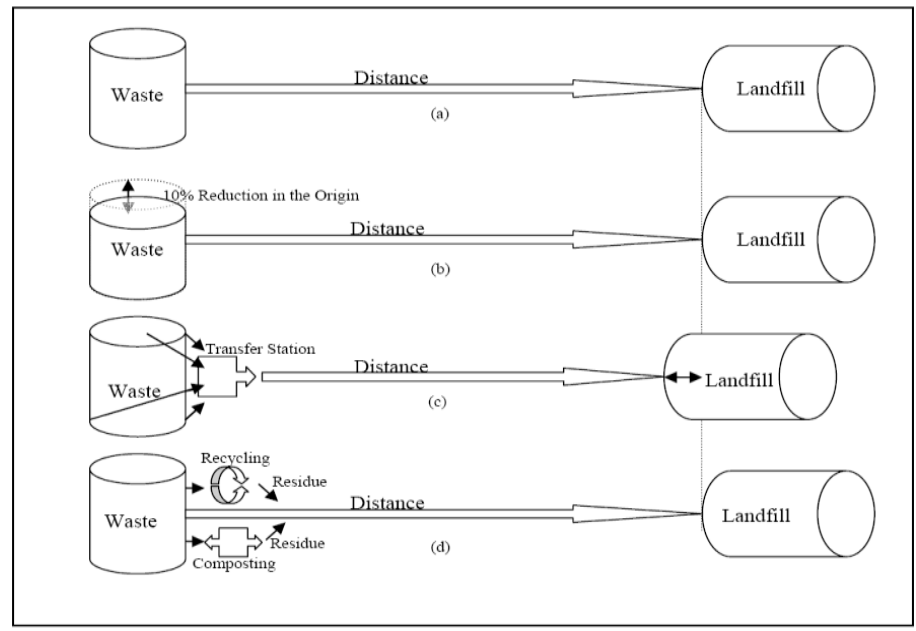

Fig 3 MSW management on the basis of landfiling the all of current produced waste (a). MSW management in Collection System Optimizing (b). MSW management in Transport System Optimizing (c). MSW management in Waste Processing System Optimizing (d).

Life Cycle Invento: Life Cycle Inventory, presented in the three mentioned scenarios, has been offered by Haight et al (2004) using the IWM_1 model. This model is composed of two sub models, economical and environmental (Stypka, 2001). In present study only the environmental sub model was used.

Life Cycle Impacts Assessment: In Life Cycle Impacts Assessment result of inventory a life cycle, converts to objective units and consequently managerial form would be achieved. So far, to perform life cycle impact assessment, a unique methodology and standardization having global acceptance, is not presented (Hofstetter, 2000b). This is due to that necessary information (spatial and temporal) in order that life cycle impact assessment might be done, does not exist (Hertwich \& others, 2000) and scientific methods for long time assessment, is not provided. (Seppälä, 2003). Practically, the only approach used since the 1990s has been "lesser is better. In this approach it is assumed that all values from one type of tension gathered due to their initial dangerous traits - without considering the place and time of tension and that the achieved values of tension are higher or lower than threshold- cause harmful changes in the environment (White et al, 1997). Overall, life cycle impact assessment is done according to the standard of ISO 14043, Through the four steps shown in figure 4 .

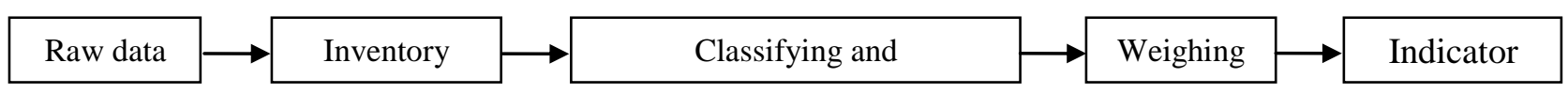

Fig 4 stages of Life Cycle Impact Assessment

Interpretation: Interpretation is the last stage of LCA to be done, besides the three previous stages. In this stage data is analyzed. Interpretation of the LCA includes reviewing all the stages of LCA.

\section{RESULTS AND DISCUSSION}

The model of IWM is run for each of the above mentioned scenarios. In order to perform the quantitative comparison of the scenarios and relevant alternatives, inventoried value allocated to impact classes considered for this purpose. Therefore each impact class in inventoried values, were normalized based on the rate of managed waste in each scenario and alternative. These values were multiplied by the characterizing factors to calculate the inventoried values in each achieved impact class as per the unit.
The next stage, achieved indicators in each class, were multiplied by the proportional weight of that class to put the additive indictors together. Based on the equivalent unit or ecological indicator, environmental load of each class was calculated. Calculated values are shown in tables 1, 2 and 3, without dimension and for comparing the scenarios and different alternatives. Ecological indicators as quantitative criteria are used for comparing the environmental load for each of the scenarios. Each scenario acquired lower point has a lesser load.

Table 1: Environmental load of the scenario (1) on the basis of Ecological Indicators

\begin{tabular}{|l|l|l|}
\hline Scenario 1-A & Scenario 1-B & Scenario 1-C \\
\hline $\mathbf{1 9 . 8 2 1}$ & 20.020 & 19.796 \\
\hline
\end{tabular}


Table 2: Environmental load of the scenario (2) on the basis of ecological indicators

\begin{tabular}{|l|l|}
\hline Scenario 2-A & Scenario 2-B \\
\hline $\mathbf{1 9 . 8 2 1}$ & 19.618 \\
\hline
\end{tabular}

Table 3: Environmental load of the scenario

(3) on the basis of ecological indicator

Results are shown in figures 5 to 10 of which the witness alternative of the scenario 2 and 3 has been omitted to have better presentation of the changes in each impact class applying the management in different sections of collecting, transportation and processing.

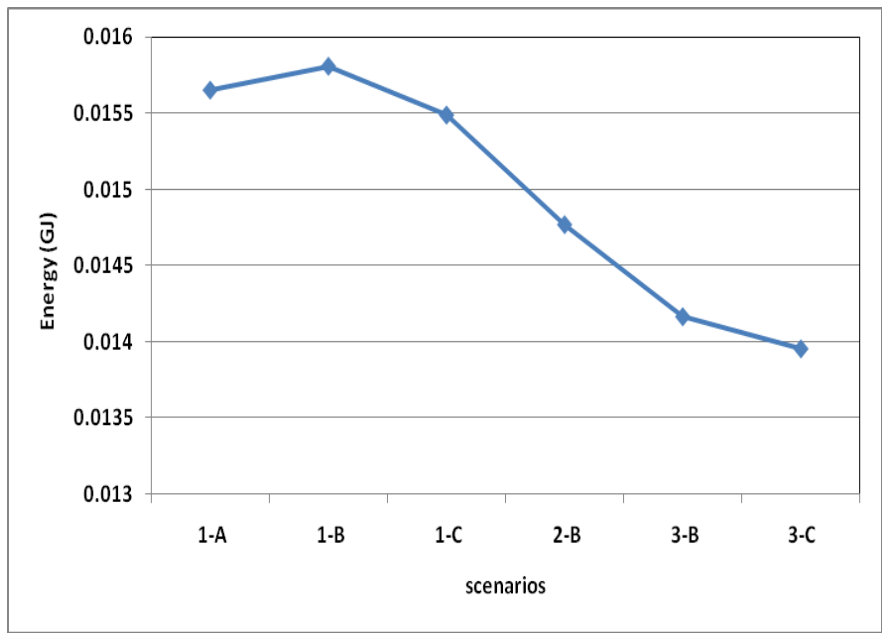

Fig 5:Changes of energy use of impact classes, applying the management in different phases of collecting, transportation and processing

Figure 6 shows that the most economical use of energy is achieved from recycling (scenario3-C) and besides the economizing in energy use, considers the waste as an invaluable source.

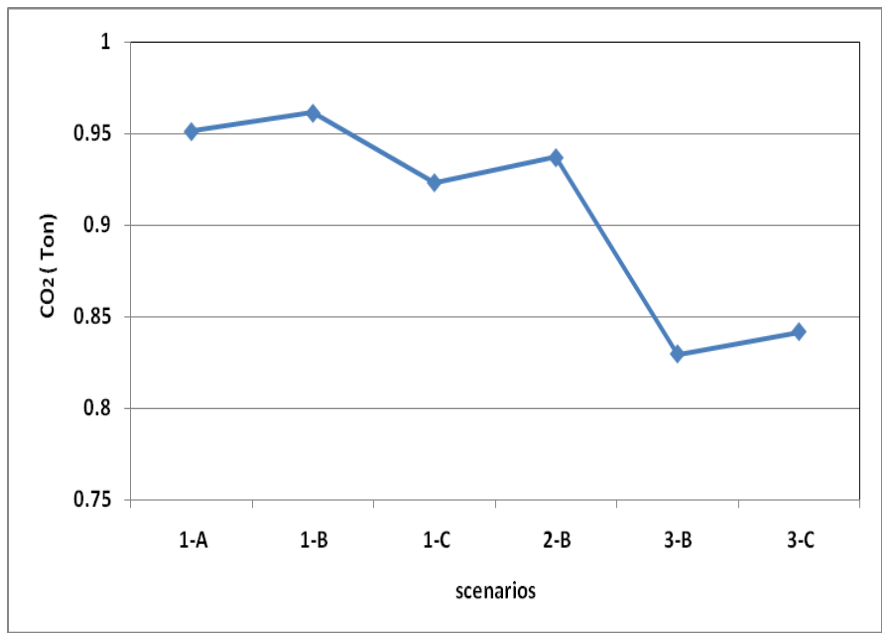

Fig 6: Changes of impact classes of greenhouse gases, applying the management in different phases of collecting, transportation and processing

As it is clear in figure 6, composting emits the least amount of greenhouse gas (scenario3-B) so that if this process is properly done, methane will not be produced. Methane, which is produced from the anaerobic decomposition process of the organic matter, has 21 times more potential of greenhouse effect than CO2 (IPPC, 1996). Furthermore, composting leads to a reduction of input volume of waste to landfills (Haight, 2004). Scenario 3-C has reduced the emission of greenhouse gases by $12 \%$ 
per ton of managed waste showing the effective role of recycling in reduction of greenhouse gases.

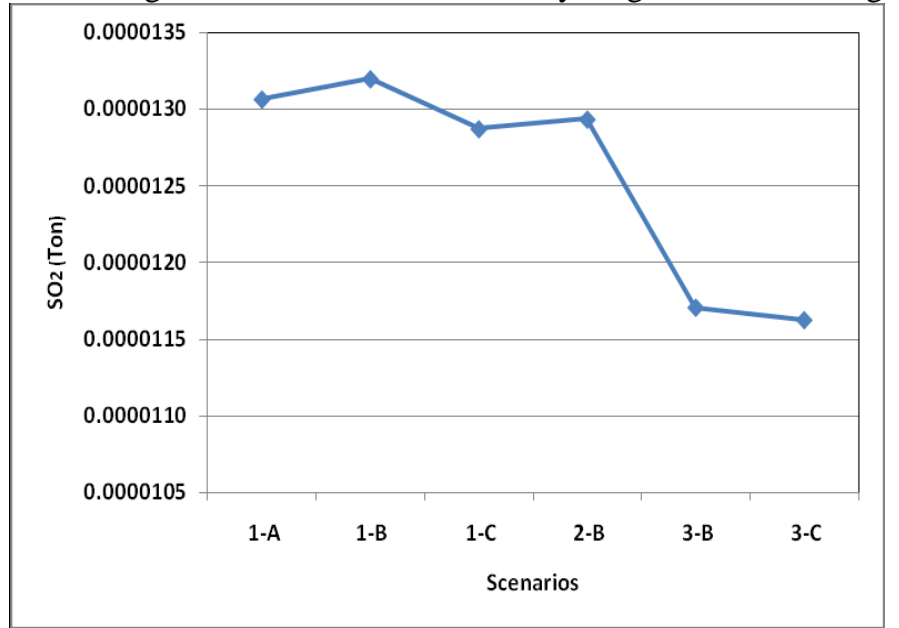

Fig 7 Changes of impact class of acidic gases applying the management in different phase of collecting, transportation and processing

Figure 7 shows that composting (scenario3-B), has reduced the production of acidic gases by $11 \%$ per ton of managed waste showing the effective role of composting in reduction of acidic gases. This reduction is due to the reduction of $\mathrm{H}_{2} \mathrm{~S}$ from anaerobic decomposition of corruptible material and also because of the reduction of energy used for the waste treatment. The highest rate of reduction of acidic gases refers to the recycling scenario (scenario3-C) near to the rate of reduction for scenario 3-B.

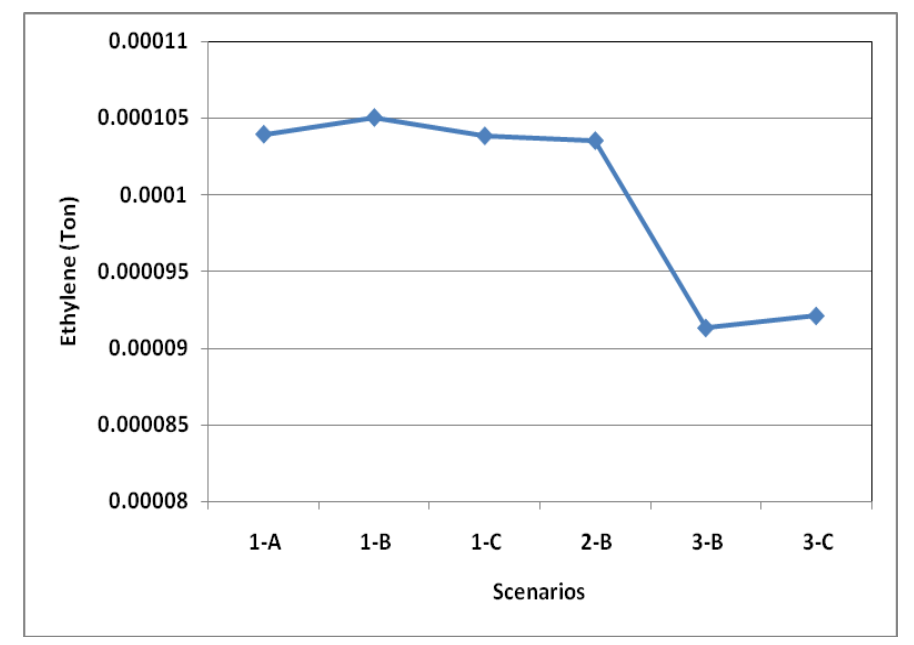

Fig 8 Changes of impact classes of photochemical smog, applying management in different phases of collecting, transportation and processing

Figure 8 shows the role of transmission stations in Waste Management along with a little reduction in the photochemical smog production in comparison with distance shortened from the source (scenario 2B) and toward the current state, it shows the reductive trend. Composting shows the least rate of photochemical production due to the reasons described above (scenario3-B). Recycling has reduced the production of photochemical smog through the reduction of the waste transported into the landfill (scenario3-C) by (more than) $10 \%$ per ton showing the positive role of the recycling process in reducing the of photochemical smog. 


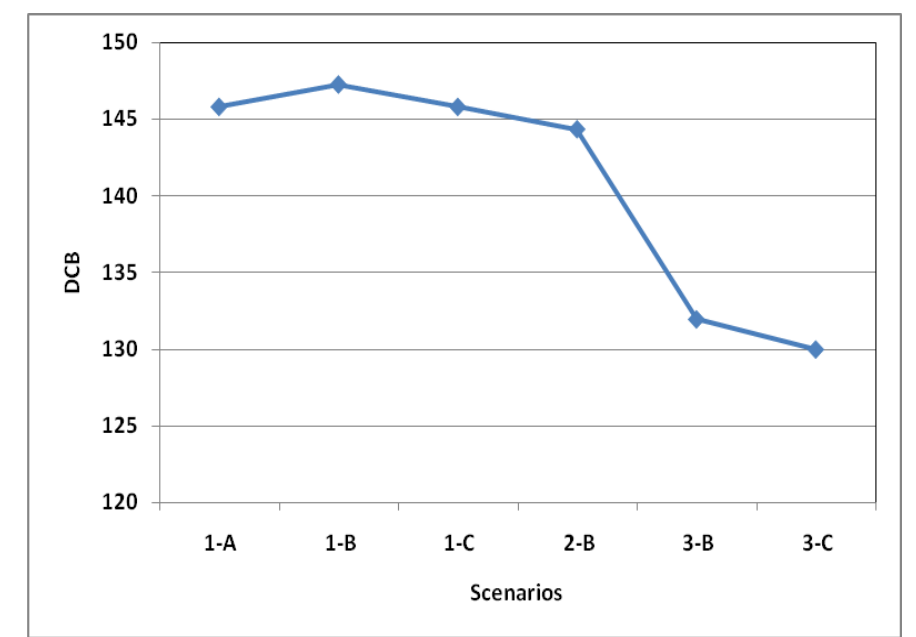

Fig 9 Changes of impact classes of toxic output of water and air applying management in different phases of collecting, transportation and processing

Figure 9 generally shows the similar trend shown in figure 5 with the difference being that the negative slope of toxic outputs from scenarios 1-B, 1-C and 2$\mathrm{B}$ has the slower trend so that scenario 1-C (reduction of waste transmitted into the landfill and reduction of distance) and 2-B (using the transmitting stations) has lesser effect towards the composting and recycling.

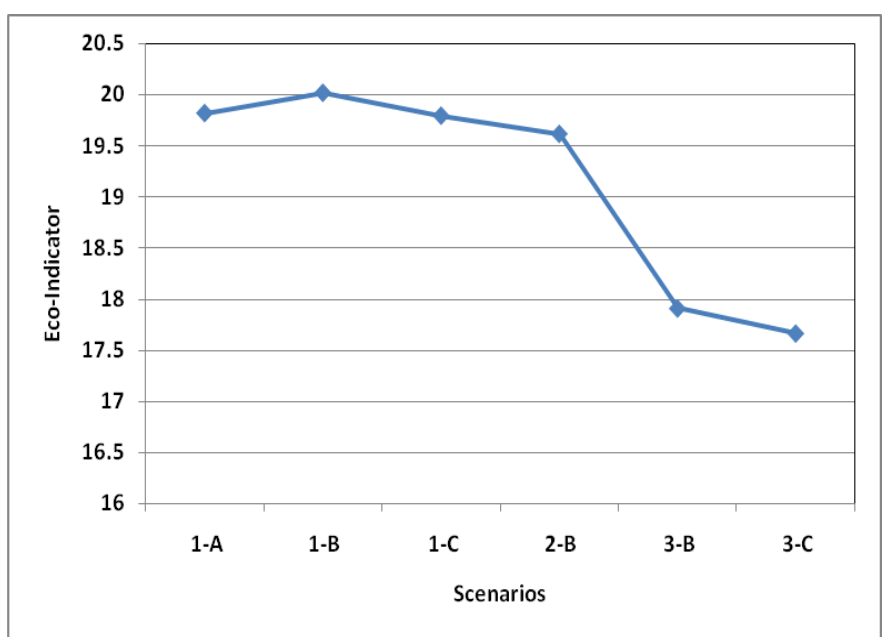

Fig 10 Changes of ecological indicators applying management in different phases of collecting, transportation and processing

The ecological indicator of the environmental load in each of the scenarios and alternatives considered is the overall consequence of actions and interactions of life cycle of solid waste. Results of this indicator explain the arrangement of the environmental preference of each phase and waste managerial processes. As it clear, in figure 10, the effect of applying the management for waste is as follows:

By reducing the waste transmitted to the landfills with constant distance (scenario2-B), due to the using of transmission stations for each managed waste per ton (normal value), ecological indicators have been decreased. It means that the ecological indicator justifies the positive role of transport stations in reducing the imposed load on the environment. Composting has decreased the ecological indicator (scenario3-B) showing the effective role of composting in reduction of environmental impact. The least value of ecological indicators refers to the scenario of recycling processes (scenario3-C).

Conclusion: Regarding to the results recycling is one of the best alternatives for Waste Management. Furthermore, composting has an important role in alleviating the load of pollutants and energy usage in the Waste Management system.

\section{REFERENCE}

Haight,, Murray. 2004Technical Report: Integrated Solid Waste Management Model. School of Planning. University of Waterloo. Canada. 
International Standard, ISO 14040,1997 Environmental management-life cycle assessment, Principles and Framework.

International Standard, ISO 14041, 1998. Environmental management-life cycle assessment, Goal and Scope Definition and Inventory Analysis.

International Standard, ISO 14042,2000. Environmental management-life cycle assessment, Life Cycle Interpretation.

International Standard, ISO 14043, 2000. Environmental management-life cycle assessment, Life Cycle Impact Assessment.

IPCC, 1996: Guidelines for National Greenhouse Gas Inventories Workbook. International Panel on Climate Change.

Ozeler. D., U. Yetis., G.N. Demirer. 2005. Life Cycle Assessment of MSW Management Methods: Ankara Case Study. Environmental International. 405-411

Powell, J., 2000. The potential for using life cycle inventory analysis inlocal authority waste management decision making. Journal of Environmental Planning and Management 43, 351-367.

Seppälä, J,.2003. Life Cycle Impact Assessment Based on Decision Analysis. PhD thesis, Helsinki University of Technology.71pp

SETAC, 1998. LCA News. Vigon B. (Ed.), V.18(6). www.setac.org.
SimaPro 6, Pre' Consultants BV, Amersfoort, The Netherlands, 2004. Avialble from : www.pre.nl.html

Stypka, T,. 2001 Adopting the Integrated Waste Management Model(IWM-1) Into The Decision Process, Institute of Heat Engineering and Air Protection, Cracow University of Technology. Warszawska 24, 31-155 Cracow, Poland

Francesco Cherubini,, Silvia Bargigli , Sergio Ulgiati.,2007. Life cycle assessment of urban waste management: Energy performances and environmental impacts. Waste Management xxx (2007) $\mathrm{xxx}-\mathrm{xxx}$

Hertwich, E.G., Hammitt, J.K. \& Pease, W.S. 2000. A theoretical foundation for life-cycle assessment.Journal of Industrial Ecology 4(1): 13-28.

Hofstetter, P., Braunschweig, A., Mettier, T., MüllerWenk, R. \& Tietje, O. 2000b. The mixing triangle:correlation and graphical decision support for LCA-based comparisons. Journal of IndustrialEcology 3(4): 97-115.

White P.R., Franke M., Hindle P. (1997). Integrated Solid Waste Management - a Lifecycle Inventory Blackie Academic \& Professional. Blackie Academic \& Professional, London. 